\title{
UM OLHAR SOBRE A ESCRITA DE RUA NO BRASIL
}

\author{
Rafael José Triches Nunes ${ }^{1}$
}

\section{Resumo}

Este trabalho se trata de um recorte do estudo ${ }^{2}$ realizado para obtenção do título de Mestre em Educação e tem por objetivo apresentar o percurso histórico da escrita de rua, termo que compreende tanto as inscriçóes urbanas chamadas de grafite, quanto aquelas conhecidas como pichação. A escrita de rua se destaca entre os diversos signos distribuídos pelo cenário urbano ao espalhar frases, formas e cores pela cidade e é colocada na tênue fronteira entre arte e vandalismo. Como concepção metodológica, optou-se por abordar aspectos da escrita de rua, desde o movimento estudantil francês de Maio de 68 até a sua repercussão no Brasil a partir da ditadura militar, e a aproximação entre os escritores urbanos e o mercado de arte. Para isso, se fez necessário discutir a relação estabelecida entre grafite e pichação, bem como apontar para as possibilidades de articulação entre a escrita de rua e a educaçáo, seja pelas tensôes ou pelas influências que uma exerce sobre a outra.

Palavras-chave: Escrita de rua. Arte de protesto. Educação do olhar.

1 Mestre em Educação pela Universidade Federal de Goiás, psicólogo do Instituto Federal de Educação, Ciência e Tecnologia de Mato Grosso - Campus Barra do Garças. E-mail: rafael.nunes@ bag.ifmt.edu.br

2 Pesquisa orientada pelo Prof. Dr. Cristóvão Burgarelli Giovani do PPGE/FE/UFG, que originou a dissertação intitulada: "Aproximações entre Psicanálise e Escrita de Rua". 


\section{Introdução}

Os registros rupestres pareciam anunciar que arte e linguagem seriam elementos que destacariam o Homem em relação aos demais animais e, se por um lado podemos supor que os rabiscos pré-históricos deram origem à escrita, por outro podemos considerar que inauguraram a pintura como uma modalidade artística. Mas a evolução humana se deu de tal forma que hoje suas produçóes artísticas e culturais já não podem ser consideradas apenas modos de comunicar ou expressar pensamentos e sentimentos.

O surgimento de movimentos artísticos e filosóficos, somados ao avanço tecnológico, permitiu que novas técnicas fossem desenvolvidas. Foram descobertos, criados e inventados materiais, utensílios, tintas e suportes. Além disso, o homem começou a pensar locais apropriados para abrigar e expor os objetos de arte feitos por ele ou por seus antepassados, trocando as antigas cavernas por novíssimos museus e galerias, abertos, ou não, para visitação do público.

Com os avanços técnicos e mecânicos, o artista se reinventa e parece resistir diante das investidas de um sistema mercadológico que frequentemente transforma o objeto de arte em um produto comercial. O sujeito-artista náo se satisfaz com o espaço que lhe é delimitado e sua produção ultrapassa as exposiçóes em galerias.

Na contemporaneidade, algumas manifestações nos chamam atenção náo somente pelo caráter transgressor que carregam em sua origem, mas, sobretudo, pela escolha do suporte que toma emprestado e pela ousadia em resgatar o espírito do Homem das Cavernas.

Assim, neste texto, que é um fragmento do estudo realizado na dissertação para obtenção do título de Mestre em Educação, será apresentado o percurso histórico da escrita de rua - termo que compreende tanto as inscriçôes urbanas chamadas de pichaçóes, quanto as demais, conhecidas como grafites - que espalha formas e cores pela cidade e se encontra na fronteira entre arte e vandalismo.

Neste recorte metodológico, optou-se por abordar aspectos históricos da escrita de rua, a partir do movimento estudantil francês de Maio de 68 até sua repercussão no Brasil, apontando para as possibilidades de articulação entre a escrita de rua e a educaçáo, seja pelos impactos ou pelas influências que uma exerce sobre a outra.

Demarcando e ressignificando o espaço público, as escrituras urbanas podem revelar distintos sentidos, atrelados ou não à realidade de quem as 
produz ou de quem circula por seu local de inscrição. Na atualidade, museus e galerias abrem suas portas para obras e exposiçóes de escritores urbanos que, por sua vez, se encontram cada vez mais próximos do mercado de arte com a realização de inscriçóes financiadas e encomendadas.

\section{Um pouco de história}

As primeiras escritas que surgiram no cenário urbano eram anônimas e feitas a lápis ou à caneta em portas e paredes de banheiros ou carteiras escolares. Mas logo deixaram de ocupar o restrito espaço das carteiras e dos banheiros, chocando o olhar do espectador ao se propagarem pelas cidades.

A escrita de rua desafia o homem contemporâneo a decifrar um número cada vez maior de informaçóes que na paisagem urbana e em seu caráter transgressor parece questionar, entre outras coisas, quem tem direito à propriedade do espaço público (GITAHY, 2012). Dessa forma, a ousadia de gravar repetitivamente frases de protesto, como "FORA TEMER" (ver figura 1), em muros, monumentos e prédios, causa desconforto para os cidadáos, para os governantes, para a mídia, enfim, para os passantes.

Figura 1 - Inscrições em paredes da UFMT

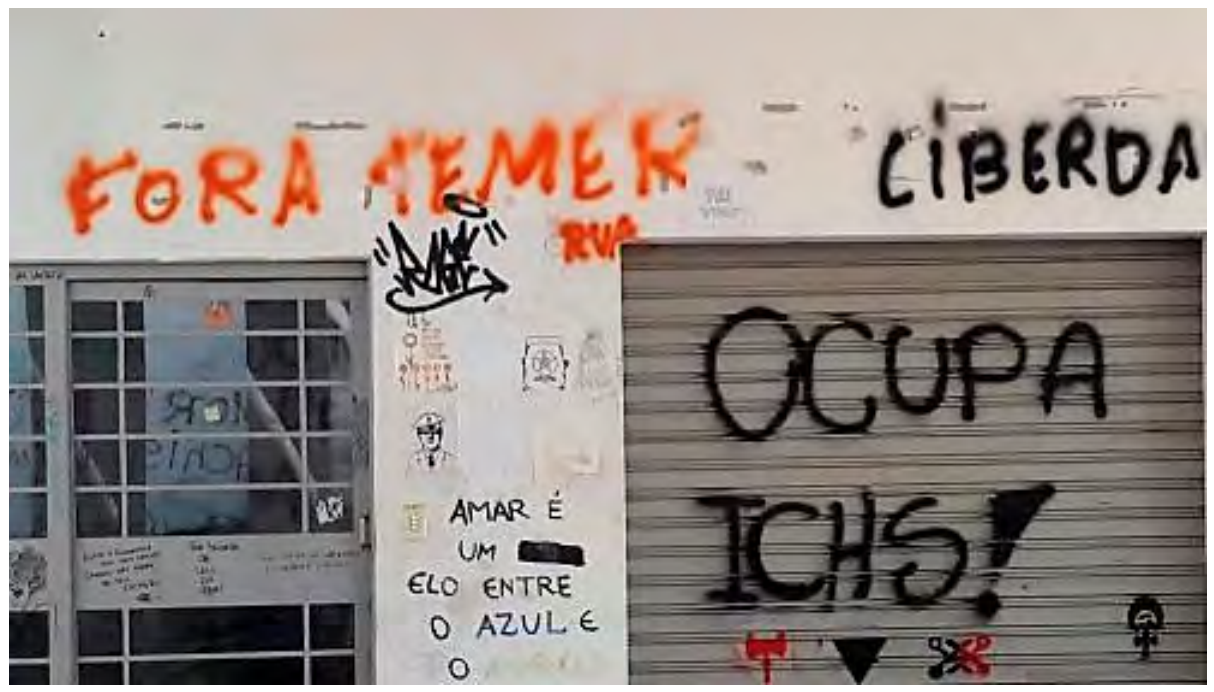

Fonte: Acervo do autor. 
Considerada uma arte marginal, uma vez que as políticas de arte urbana se demonstram conservadoras e os poucos espaços existentes são dedicados às modalidades oficiais como arquitetura e esculturas, a escrita de rua se espalha pela cidade toda e por todas as cidades. Arruda (1984) entende que o ato de escrever nas ruas pode ser individual ou coletivo, desde que recupere o uso dos muros da cidade, estimule o olhar e leve o sujeito a refletir acerca do espaço.

Assim, os escritores reinventam formas de ocupaçáo dos espaços públicos como quem brinca de ser proprietário destes territórios, ainda que por um tempo muito curto. Em meio a milhares de signos que se espalham pelas cidades, grafites e pichações destacam-se por suas particularidades, tornando-se referências no contexto urbano.

A escrita de rua, tal como a conhecemos hoje, se inicia com inscriçóes de motivação política do movimento estudantil francês de Maio de 68, todavia, há registro de inscrições do mesmo cunho encontradas na cidade do Império Romano, Pompeia, destruída pela erupção do vulcão Vesúvio no século I, cujas ruínas e inscrições foram descobertas no século XVIII. Ao ultrapassar os muros das universidades, o movimento recebeu novas influências deixando de ser caracterizado apenas por frases de protesto.

Essa escrita "que possui o vigor e a alegria de estar sempre em movimento" (LARA, 1996, p. 61) se difundiu por todo o mundo 3 , tendo ecoado fortemente também nos EUA e no Brasil, onde, como veremos à frente, ocorre uma distinção em duas categorias, a saber: grafite e pichação. Neste texto, tomou-se a opçáo metodológica de não fazer juízo entre tais categorias, abordando as inscriçóes urbanas pelo termo "escrita de rua", que contempla tanto o grafite, quanto a pichação.

\subsection{O Maio de 68}

A França encontrava-se sob o governo de Charles de Gaulle (1959-1969) quando uma onda de protestos saiu das universidades parisienses e se espalhou rapidamente pelo país, contrapondo os ideais sobre política e educaçáo estabelecidos pelo Estado, ganhando apoio das classes trabalhadoras e da sociedade em geral. O ponto alto deste movimento ficou conhecido como Maio de 68.

3 O lado ocidental do muro de Berlim, por exemplo, tornou-se um grande mural grafitado (SILVEIRA JUNIOR, 1991). 
Para questionar o sistema de poder e produção, os estudantes utilizaram-se de frases escritas nos muros como forma alternativa de comunicação com a sociedade, provocando o uso de forças repressivas por parte do governo. Essas inscriçóes foram chamadas pelos estudantes franceses de graffiti.

Por causa da repressão, as inscriçóes geralmente eram realizadas clandestinamente e durante a noite, mas a ação precisava ser estudada previamente para diminuir os riscos. Alguns fatores afetavam o trabalho realizado: "a velocidade de circulação do trânsito vai interferir no tamanho das imagens; a possibilidade de coerção, na rapidez da ação; e a velocidade da ação, na qualidade estética das inscrições” (SILVEIRA JUNIOR, 1991, p. 92).

Os jovens se posicionavam contra o controle social, criticando duramente as estruturas da sociedade baseada no capital e no consumo, e a massificação imposta aos indivíduos. "A contracultura era uma maneira de se revoltar contra a ordem vigente; as armas eram as ideias, as atitudes, o grafite e as flores" (LARA, 1996, p. 81). Ao lançar mão do uso da escrita de rua, reivindicava-se uma nova maneira de pensar e agir, impulsionando outros movimentos internacionais, como o movimento estudantil brasileiro no período do regime militar.

\subsection{Influência Hip-hop}

Tal como os gritos do movimento estudantil francês, a escrita de rua ecoou convincentemente pelo mundo e não demorou muito para chegar com força aos EUA. No princípio, foram as Tags que se espalharam pelos túneis e trens de metrô. Tag era o nome dado às marcas que funcionavam como assinaturas e indicavam o domínio de um território. Feitas com pincel atômico ou spray, elas anunciavam o nome do seu escritor e a rua onde ele morava (GITAHY, 2012). Não demorou muito para que as marcas como "TAKI 182 "4 ganhassem volume e formas distintas, tomando toda a superfície dos trens e se multiplicando por toda a cidade.

Silveira Junior (1991, p. 13) diz que:

[...] enquanto em Paris a repressão aos grafiteiros é moderada, em Nova York ela é radical. Ao mesmo tempo em que se criavam

4 Taki se tornou famoso após espalhar sua Tag pela cidade, sobre muros, portas, placas, metrôs, etc. e ser descoberto e entrevistado pelo jornal The New York Times, em 1971 (SILVEIRA JUNIOR, 1991, p. 12). 
esquadróes especiais de combate, superequipados e auxiliados por cães, o conselho municipal baixava leis restringindo a venda de spray e pincel atômico aos menores de 18 anos (...). No entanto, o fenômeno não foi atenuado e os ataques continuaram.

As paredes dos metrôs e superfícies dos trens passaram a ser revestidas com tintas e azulejos laváveis, fazendo com que as inscriçóes se tornassem composiçóes cada vez mais efêmeras ao mesmo tempo em que se tornavam mais complexas, unindo letras e gravuras ou trazendo personagens de histórias em quadrinhos para o universo das ruas (GITAHY, 2012).

Nos anos 1980, o movimento hip-hop utilizou-se do seu quarto elemento $^{5}$, o graffiti, para manifestar suas reivindicaçóes, principalmente aquelas relacionadas às questóes de igualdade social e racial. Os escritores ligados a este movimento eram negros e latino-americanos, em sua maioria, e passaram a agir coletivamente na tentativa de ampliar a chance de sucesso, devido à intensificação da perseguição policial.

Ultrapassando a fase das Tags, a escrita de rua recebeu novas influências, sofisticando-se em termos de elaboração e aproximando-se das artes plásticas. "Imediatamente a crítica, os jornalistas e a população em geral passaram a ver com outros olhos esse tipo de grafite figurativo, carregado de elementos psicológicos e com estilos definidos" (LARA, 1996, p. 84). Galerias e museus passaram a convidar nomes como Jean-Michel Basquiat e Keith Haring para exporem suas obras, aproximando os escritores urbanos e o mercado de arte.

A escrita distorcida e os desenhos feitos à mão livre que questionavam o modo de vida americano não couberam nos túneis de metrô e espalharam-se rapidamente pela cidade, sendo duramente reprimidos. A escrita de rua que emergiu da subversão e contestação encontrou nos EUA um mercado receptivo às novidades em termos de estilo. "O gesto, a liberdade de movimento, a figuração e o spray eram as novas armas contra o abstracionismo, o concretismo e outros 'ismos' que estavam na moda artística e circulavam pelas galerias" (LARA, 1996, p. 83).

5 O movimento hip-hop é composto por quatro elementos artísticos: a música com o disc-jockey (DJ); a poesia com o mestre de cerimônia (MC); a dança com o B-boy e B-girl; e a pintura com o graffiti. 


\section{A escrita de rua no Brasil}

No Brasil, o fenômeno das inscriçóes urbanas intensificou-se a partir dos anos 1970, auge da ditadura militar e da censura aos meios de comunicação. Até então limitadas às carteiras escolares, banheiros e propagandas eleitorais, as escrituras feitas nas ruas, à mão livre, que começavam a se espalhar pelas cidades eram chamadas pejorativamente de pichaçóes e "a palavra grafite só passou a ter uso corrente com o aparecimento dos desenhos feitos com máscaras” (SILVEIRA JUNIOR, 1991, p. 16). A relação entre grafite e pichação será discutida um pouco mais à frente.

As primeiras inscriçóes que surgiram eram curiosas e provocavam espanto, não só por sua aura enigmática, mas também devido à forma como se multiplicavam, com a mesma inscrição se repetindo em diversos locais. Mais tarde, uma série diversificada de inscriçóes surgiu nos arredores das universidades, interferindo no cotidiano ao surpreender o olhar dos passantes.

Apesar das influências do movimento de Maio de 68 e do movimento hip-hop, no Brasil, as inscriçóes não se resumiam ao protesto político e não elegeram um suporte único como o metrô, por exemplo.

Arruda (1984, p. 60) nos lembra que, devido aos modelos de conduta impostos pelo Estado, vivia-se sob um clima de tensão:

[...] onde pouco ou nenhum espaço sobrou à manifestação individual ou coletiva, tempos de repressão desenfreada que tentou impedir durante décadas a existência de práticas tribais e coletivas, espontâneas ou organizadas.

Dificilmente encontramos grandeza nas manifestações que ocorrem em ambientes protegidos pela censura e por seguranças fortemente armados, mas a escrita de rua parece ser impulsionada pela tentativa de censurá-la, pois "com a carência de espaço para que as pessoas possam se expressar, nada mais justo que procurar as paredes ou qualquer outra área disponível" (ARRUDA, 1984, p. 60).

Uma série de escritores de rua - estudantes, artistas plásticos, engenheiros, arquitetos, entre outros - apresentava uma proposta de intervenção diferente daquela que era malvista pela população, impregnada de frases e rabiscos, signos e símbolos quase sempre incompreensíveis, carregando o estigma de 
vandalismo. A escrita desses artistas passou a valorizar o trabalho gráfico e a figuração. Vale destacar aqui os trabalhos de Alex Vallauri, considerado pioneiro do chamado grafite figurativo no Brasil.

A Rainha do frango assado, de Vallauri, tornou-se uma personagem presente em alguns pontos da cidade de São Paulo, ora dando uma festa, ora fazendo um piquenique, quase sempre calçando uma Bota preta. Impressa por todos os lados, a bota tornou-se a marca de Vallauri, seja compondo uma figura maior, seja sozinha, como um carimbo. Tratava-se de uma figura feita com auxílio de máscara, um molde recortado em papelão ou outro material que permitia a reprodução exata da mesma figura inúmeras vezes.

O uso de máscaras representou a valorização do trabalho gráfico e da aproximação com as artes plásticas, marcando um aparente distanciamento entre as escritas do grafite figurativo e aquelas que permaneciam sob o rótulo pejorativo de "pichação".

Os escritores de rua contemporâneos de Alex Vallauri são chamados de primeira geração de escritores e foram responsáveis pela produção de trabalhos que valorizaram a arte gráfica e provocaram o debate em torno da distinçáo entre a pichação e o grafite figurativo ${ }^{6}$.

Além do trabalho com a utilização de máscaras e descrição de figuras que traziam elementos cotidianos, também foram notáveis os de livre figuração, feitos à mão livre - como os seres extraterrestres de Rui Amaral - e os da escrita com ênfase em personagens de histórias em quadrinhos - como as reproduções de Tintin por Carlos Matuck.

A segunda geração de escritores de rua não apresentou tantas inovaçóes relacionadas às técnicas ou vertentes, apesar da influência do movimento hip-hop. Com o lema "um spray na mão e uma ideia na cabeça", passaram a atuar em grupos e as inscriçôes geralmente faziam sentido somente para o próprio grupo.

Durante esse período também aconteceu uma espécie de profissionalização da escrita de rua em decorrência da aproximação com as artes plásticas; escritores de rua foram convidados a expor durante a XVII Bienal de Artes de São Paulo, por exemplo. A escrita de rua começava a alcançar padróes diferenciados, porém os investimentos feitos em arte urbana eram e ainda são consideravelmente inferiores se comparados aos recursos investidos em galerias de arte e museus (LARA, 1996).

6 Posteriormente chamado apenas de grafite, deixando o termo pichação nomear exclusivamente as inscrições pouco elaboradas, anônimas e não autorizadas. 
Assim, a terceira geração de escritores de rua pode ser reconhecida como artística e muitos escritores produzem trabalhos comerciais, inclusive por encomenda, mas não se limitam a essa atividade e, por isso, as intervençóes não autorizadas permanecem sendo gravadas pelos muros. A repressão policial ainda ocorre, embora seja menor se comparada ao início do movimento.

Muitos desses escritores exercem a escrita de rua como a única atividade profissional, alguns dedicam parte do tempo a outra atividade e atuam como tatuadores e ilustradores, por exemplo. Utilizar o pagamento recebido por um trabalho para custear uma intervenção não autorizada é um hábito comum entre os escritores para conseguirem "subsidiar parte de sua produção marginal com verbas vindas da remuneração obtida com trabalhos encomendados" (LARA, 1996, p. 136).

Os escritores de rua adotavam marcas e estilos pessoais que permitiam suas identificaçóes e, a partir da terceira geração, as inscriçóes começaram a ser assinadas por seus autores. Esta atitude era considerada "ousada e extremamente perigosa, como eram também as primeiras teorias e postulados que questionavam a forma da Terra ou a órbita dos astros" (LARA, 1996, p. 66). Artistas brasileiros como Eduardo Kobra, Os Gêmeos e Paulo Ito, tornaram-se referências no universo da escrita de rua.

Aparentemente, o distanciamento conceitual entre grafite e pichação foi realizado com sucesso, imprimindo noçóes de bem e de mal para as duas partes de um único todo, pois o picho permanece reprimido e seus escritores são tratados como vândalos. Mas as inscrições, como um todo, fazem as ruas gritarem, dando voz ao que não pode ser dito, a um desejo que náo cessa de se inscrever. Assim, a escrita de rua assume uma representatividade política e cumpre, a seu modo, o duplo papel de ser arte de libertação e de protesto.

\subsection{Grafite e pichação}

Os estudantes franceses denominaram graffiti as frases e figuras que gravavam nas ruas, representando os ideais daquele grupo. Na França de 1968 tudo era graffiti. O termo pichaçáo foi empregado no Brasil, de forma pejorativa, para criticar a escrita de rua que se proliferava abundantemente pelas cidades, enquanto o termo graffiti passou a ser usado com maior frequência a partir da aproximação entre escrita de rua e artes plásticas. 
O termo original, emprestado da língua italiana, designava um conjunto de inscrições que, no Brasil, foram chamadas primeiro de pichação e, posteriormente, foram categorizadas em grafites figurativos e pichaçôes (SILVEIRA JUNIOR, 1991). Mas o nome dado às escritas das ruas parecia pouco importar para quem as escrevia e assim expressavam Matuck e Zaidler, respectivamente:

A divisão entre grafite e pichaçôes é uma bobagem, não tem nada a ver. Acho que é só uma questão de língua. Grafite é um termo mais erudito, digamos, para a pichação. É um termo estrangeiro. O que se faz é pichação, não importa se é escrito ou desenhado. (Apud SILVEIRA JUNIOR, 1991, p. 60).

É a mesma coisa. Não seria problemático falar grafite para a coisa com imagem e pichação para a coisa escrita. Então fica essa coisa: os grafiteiros sim, os pichadores não. Que papo é esse? Não é todo mundo saindo na rua e fazendo uma intervenção do mesmo jeito? (Apud SILVEIRA JUNIOR, 1991, p. 60).

Nos anos 1980, promoviam-se debates nos quais a população se mostrava dividida entre apoiar e incriminar grafiteiros e pichadores (MILLER; VIEIRA, 1980). Ouviam-se discursos pedindo intervenção federal, até mesmo de líderes religiosos, pois as prefeituras já não conseguiam lidar com a situação, afirmavam que os escritores agrediam o cenário urbano e tratavam o fato como um modismo delinquente.

De outro lado, havia os que defendessem as inscriçôes afirmando que os escritores urbanos não poderiam ser culpados pela má qualidade de vida oferecida aos cidadãos (ARRUDA, 1984).

A categoria de inscriçôes que passou a ser chamada de grafite figurativo valorizava as cores e formas, destacando-se ante as outras, e despontou como uma estratégia de publicidade barata e eficaz para o circuito alternativo de divulgação de shows de música, espetáculos de dança ou teatro. Os anúncios eram gravados diretamente nos muros ou estampavam cartazes de divulgaçáo.

As demais escritas continuavam sem poder contar com a simpatia da população e, por isso, permaneceram sob a alcunha de pichação, carregando o estigma de vandalismo. Dessa forma, esse termo passou a representar um tipo de comunicação fechada, com linguagem codificada e com significado 
restrito aos próprios grupos envolvidos, destacando-se pela frequência e pelos locais do cenário urbano onde se inscreviam.

As ditas pichaçóes são representaçóes de siglas, nomes e apelidos, individuais ou de grupos, geralmente são garatujas grafadas em locais cada vez mais altos e perigosos. Jovens escritores, geralmente entre 10 e 20 anos $^{7}$, espalhavam suas assinaturas por prédios e monumentos públicos, provocando repercussóes midiáticas.

A mídia maldizia as pichaçôes que se espalhavam pelo espaço público, ocupando os ambientes reservados para a publicidade ou para a arte pública oficial, acumulando-se umas sobre as outras e fazendo com que seus autores se arriscassem cada vez mais, na busca pela inscrição de maior destaque (CEARÁ; DALGALARRONDO, 2008). Outro meio de obter um "ibope" maior era gravar suas marcas no alto de prédios, um método arriscado, mas "o sabor das alturas e o desafio à gravidade instigam os pichadores” (SILVEIRA JUNIOR, 1991, p. 83).

Assim, enquanto o grafite figurativo era cooptado pela mídia para a publicidade, a dita pichação tornou-se alvo das manchetes policiais, sendo perseguida e criminalizada. Os grafites entravam no museu e anúncios publicitários, enquanto alguns pichadores - como Juneca, Pessoinha e Bilão - tornaram-se famosos por seus atos, por desafiarem as sançóes presidenciais, inspirando jovens de classes socialmente excluídas e criando uma identidade entre a escrita de rua e a periferia (GITAHY, 2012).

A legislação vigente no Brasil criminaliza a pichação, no artigo 65 da Lei n. 9.605, de 12 de fevereiro de 1998, aplicando multas e até mesmo detençáo de três meses a um ano, mas permite o grafite quando é realizado com autorização do proprietário ou do poder público, valorizando o patrimônio.

Ou seja, no Brasil, a distinção entre grafite e pichação é estabelecida pelo texto da lei, tendo como centro a existência de autorização prévia e possível valorização patrimonial. Assim, “o termo 'grafite', passa a ser privilégio das inscriçôes figurativas, que ganham status de 'arte de rua', todo o 'resto' fica classificado como 'pichação"' (SILVEIRA JUNIOR, 1991, p. 66).

Durante a gestão do então presidente Jânio Quadros, tentou-se negociar a liberação de determinados espaços públicos para a escrita de rua. Parecia um avanço para coibir a proliferaçáo descontrolada das escrituras, mas foi

7 Os pichadores geralmente eram menores de 18 anos. Os mais velhos paravam de pichar e os grupos adotavam membros mais jovens para espalharem suas marcas. Tratava-se de uma estratégia para se esquivarem da polícia e dos processos. 
frustrada porque os escritores não permitiram uma domesticação completa do caráter transgressor de seus atos.

Além disso, essa estratégia acabou por promover uma perseguição às pichaçóes, pois tinha como proposta que as pichaçóes existentes no cenário urbano fossem cobertas pelos grafites figurativos, o que provocou tensóes no seio do movimento, como esclarece Sou Pipou:

Muitas vezes os grafiteiros aparecem dando reportagem e tudo mais, e começam a meter o pau nos pichadores. Daí os moleques se revoltam, num tão nem aí mesmo e começam a rabiscar os grafites dos grafiteiros. E é o que mais acontece hoje em dia, porque os grafiteiros falam que os pichadores táo tomando espaço deles, que não sei o quê. E sempre tão dando umas reportagenzinhas daquelas e metendo o pau nos pichadores... Os repórteres perguntam a diferença entre grafite e pichaçóes e eles acabam criticando os pichadores. Aí os pichadores vão lá e rabiscam os grafites dele. (Apud SILVEIRA JUNIOR, 1991, p. 73).

Visando a um pacto pela não interferência nos trabalhos realizados, ao empreenderem trabalhos comerciais, os grafiteiros passaram a doar o material que sobrava aos pichadores. Mas a perseguição aos pichadores por parte da polícia permanece intensa até os dias de hoje, criando um clima de medo, pois os noticiários revelam assassinatos de pichadores e detençóes que sáo acompanhadas de espancamento e de "banhos de spray".

É possível apontar, ao longo dos anos, que a presença de governos mais conservadores e austeros traz como característica a perseguição aos movimentos de rua e a tentativa de repressão às manifestaçóes e expressóes populares, enquanto que a presença de uma gestão mais democrática pode representar a abertura de diálogos com a comunidade. Assim, a política indo ao encontro da escrita de rua torna-se um dos temas que se faz atual nas representaçóes, seja por meio de textos ou gravuras.

Um fato curioso é que, quanto mais a política atua para censurar a arte, mais original e revolucionária ela se torna, pois é desafiada a encontrar meios para driblar tais censuras. Com isso, as escritas de rua devem ser compreendidas como um grito que insiste em ecoar pelos muros da cidade, mesmo quando procuram barrá-lo.

8 Esvaziamento dos tubos de spray no corpo dos pichadores. 


\section{Escrita de rua e educação}

Caracterizada por ser um ruído no contexto urbano e pelo choque que causa no olhar do espectador, a escrita de rua tem suas origens num movimento de contracultura, quando inúmeras entidades se utilizaram de inscriçóes murais para divulgar ideias, marcar um território ou simplesmente colorir o lugar.

Aos poucos, passou por um processo de legalizaçáo parcial com o grafite, enquanto a pichação permanece proibida, e de aproximação com as artes plásticas. Na tentativa de controlarem e disciplinarem a prática, alguns gestores criam espaços públicos onde as inscriçóes são permitidas.

Os novos códigos que ocupam as ruas parecem bastante distanciados dos ideais do movimento estudantil francês do qual originaram. A escrita de rua exige que o escritor reinvente formas de ocupar a cidade, passando a fazer parte das experiências cotidianas das pessoas ao afetá-las, produzindo sentidos e provocando reflexóes sobre o estilo de vida na sociedade moderna e sobre a política.

Cabe mencionar que, nos debates em torno das artes, há quem defenda que política e arte mantenham-se à distância, mas sendo a arte também um ato político, é natural que a política surja como tema a ser representado nas obras de arte, fazendo com que o espectador saia de uma posição passiva e interaja diretamente com as obras, revelando a capacidade formativa da arte, na contramão da manipulação de informaçóes veiculadas nos meios de imprensa.

A arte, em seus mais variados formatos, demonstra capacidade de diálogo com o público para desvelar a realidade, tomando-a como objeto de contemplação e reflexão. As atividades artísticas, em especial a escrita de rua, demonstram um potencial para colaborar, formal ou informalmente, com os meios educacionais encontrados na sociedade.

Com a vida cotidiana se tornando cada vez mais complexa e mecanizada, dividida e subdividida em classes e interesses, o sujeito se vê imerso em uma suposta felicidade proporcionada pelo avanço tecnológico dos meios de produção, que, em seu discurso, pretende superar qualquer limite e suprir qualquer falta. Mas, em sua essência, o sujeito permanece marcado com a falta simbólica de seu objeto de desejo inconsciente e, na busca por esse objeto, o homem se vê buscando um domínio cada vez maior das técnicas e tecnologias que ele mesmo cria. 
A produção artística e cultural se faz presente na história da humanidade desde os tempos mais remotos. $\mathrm{O}$ homem primitivo não tinha noção do movimento que inaugurara ao inscrever a si mesmo nas paredes das cavernas. Atualmente, muito tempo depois de substituir a vida na caverna por uma sociedade dividida em classes, a arte ainda carrega um caráter místico.

Dessa forma, a ausência das experiências artísticas representaria um empobrecimento dos sentidos e dos afetos. Assim, o artista é o sujeito que permite ao homem experimentar a realidade, compreendê-la, suportá-la e, também, transformá-la.

O contato com a arte é um contato com o outro e possibilita compreender o que há de singular. Nesta perspectiva, destaca-se o papel educativo, devendo a educação ser considerada como uma prática para além dos muros da escola, uma prática que visa à formação de sujeitos, sobretudo, autônomos e com capacidade crítica suficiente para sustentarem seus desejos, desenvolvendo identidades individuais, sociais e culturais. Fischer (1983, p. 7) complementa essa concepção ao declarar que:

Compreender a educação, numa perspectiva cultural e de totalidade social, é ir para além dos muros da escola, interrogando-a sobre suas finalidades, normas, políticas de gestão organizacional e dos processos de ensino aprendizagem, projeto, produção educativa, visóes de homem, de mundo e de sociedade; indagando-a sobre limites e aprendizagens de produção de um conhecimento emancipador; é incursionar sobre uma escola aprendente, é arriscar romper com paradigmas positivistas e funcionalistas de determinação e fragmentação da realidade e situá-la como espaço ecológico de cultura, construindo uma nova linguagem de entendimento da função social e cultural da própria escola.

Sublinha-se que estabelecer uma relação entre educação e escrita de rua não se trata de discipliná-la, o intuito deve ser inserir o sujeito em uma perspectiva cultural singular e permitir que ele se integre à cultura do mundo à sua volta. É importante que a aprendizagem mediada pela arte náo se limite aos muros da escola e, sim, que esta ultrapasse este contexto, no qual o sujeito seja levado a experimentar outras formas de aprendizagem, apreciar outras expressóes artísticas e, assim, desenvolver uma espécie de educação do seu olhar. 
Aguirre (2012, p. 175) mostra que atualmente a escrita de rua tem "sido tomada como uma oportunidade para trazer ao mundo da educação setores juvenis em risco de exclusão social ou simplesmente desmotivados ou alheios aos saberes escolares". Vale destacar que a inclusão do componente curricular Artes no sistema de ensino brasileiro facilita o desenvolvimento de atividades relacionadas à escrita de rua, mesmo em ambientes escolares, apesar do baixo investimento em formação e qualificação dos professores.

Educar o olhar compreende pensar as representaçóes de arte como parte de um programa de produção de imagens capaz de reproduzir as imagens de nossas memórias, capaz também de alterar a realidade; compreende pensar sobre as origens da produção industrial da cultura.

Considerando tal perspectiva, a educação informal, fora dos muros da escola, possibilita uma constituição humana carregada de sentidos e afetos, ou seja, busca a formaçáo de um ser humano pleno, valorizando náo apenas o seu físico ou o intelecto, mas também a sensibilidade e os aspectos éticos que são concebidos na relação que se estabelece com o outro e com a cultura em que ele se insere.

\section{Considerações finais}

A construção da subjetividade na atualidade é perpassada por uma enorme quantidade de aparelhos que disparam todo tipo de imagens em um fluxo veloz e contínuo - televisão, cinema, computador, outdoors, encartes de propaganda, artes de rua, etc. - e diariamente os sujeitos relacionam-se com elas de alguma maneira.

Essa variedade de informaçóes visuais possibilita e favorece a construção e a produção de sentidos sobre a experiência do sujeito, podendo também provocar debates audaciosos sobre os conteúdos manifestos nas artes e produzindo uma reflexão crítica sobre os valores contemporâneos.

Sendo assim, é importante compreender a escrita de rua a partir de sua capacidade de comunicação e diálogo com o espectador que possibilita uma renovação do saber e da sensibilidade. É também importante considerar que essa escrita permite a associação entre a comunidade e o território ocupado, dando novos significados ao espaço através dos signos e códigos gravados nas ruas.

Por fim, considerando sua origem como arte de protesto e seu caráter subversivo, bem como o potencial de formação de consciência crítica e pro- 
dução de autonomia, a escrita de rua educa o olhar ao oportunizar vistas e vivências, fazendo o sujeito emergir em meio aos espaços públicos, instigando-o a ter contato com essa modalidade de arte e a reproduzi-la, tornando-se ativo e autônomo.

\section{REFERÊNCIAS}

AGUIRRE, Imanol. Experiência estética e transmissão de saberes associados ao grafite juvenil. In: MARTINS, Raimundo; TOURINHO, Irene. Culturas das imagens: desafios para a arte e para a educação. Santa Maria: Editora UFSM, 2012.

ARRUDA, Valdir. Um spray na mão e uma ideia na cabeça. Arte em Revista, São Paulo, n. 8, 1984.

BRASIL. Lei n. 9.605, de 12 de fevereiro de 1998. Dispóe sobre as sançôes penais e administrativas derivadas de condutas e atividades lesivas ao meio ambiente, e dá outras providências. Disponível em: <http://www.planalto.gov.br/ccivil_03/leis/L9605.htm> Acesso em janeiro de 2018>. Acesso em: 1 mar. 2017.

CEARÁ, Alex de Toledo; DALGALARRONDO, Paulo. Jovens Pichadores: perfil psicossocial, identidade e motivaçáo. Psicologia, São Paulo, n. 19, v. 3, jul.-set. 2008.

FISCHER, Ernst. A necessidade da arte. Rio de Janeiro: Zahar, 1983.

GITAHY, Celso. O que é graffiti. São Paulo: Brasiliense, 2012.

LARA, Arthur Hunold. Grafite: arte urbana em movimento. 1996. Dissertação (Mestrado). São Paulo: USP-SP, 1996.

MILLER, Cláudio; VIEIRA, José. A cidade pergunta. Jornal da Tarde, São Paulo, p. 11, 8 mar. 1980.

SILVEIRA JUNIOR, Nelson Eugênio da. Superfícies alteradas: uma cartografia dos grafites na cidade de São Paulo. 1991. Dissertação (Mestrado em Antropologia Social)-Unicamp, Campinas, 1991. 